\title{
The insect central complex as model for heterochronic brain development-background, concepts, and tools
}

\author{
Nikolaus Dieter Bernhard Koniszewski ${ }^{1,2}$ - Martin Kollmann ${ }^{3}$ Mahdiyeh Bigham ${ }^{1}$. \\ Max Farnworth ${ }^{1}$ - Bicheng $\mathrm{He}^{1}$ • Marita Büscher $^{1}$ - Wolf Hütteroth ${ }^{3,4}$. \\ Marlene Binzer $^{3} \cdot$ Joachim Schachtner $^{3} \cdot$ Gregor Bucher $^{1}$ (i)
}

Received: 8 February 2016 / Accepted: 17 March 2016/Published online: 7 April 2016

(C) The Author(s) 2016. This article is published with open access at Springerlink.com

\begin{abstract}
The adult insect brain is composed of neuropils present in most taxa. However, the relative size, shape, and developmental timing differ between species. This diversity of adult insect brain morphology has been extensively described while the genetic mechanisms of brain development are studied predominantly in Drosophila melanogaster. However, it has remained enigmatic what cellular and genetic mechanisms underlie the evolution of neuropil diversity or heterochronic development. In this perspective paper, we propose a novel approach to study these questions. We suggest using genome editing to
\end{abstract}

Communicated by Angelika Stollewerk

This article is part of the Special Issue "Size and Shape: Integration of morphometrics, mathematical modelling, developmental and evolutionary biology", Guest Editors: Nico Posnien-Nikola-Michael Prpic.

Nikolaus Dieter Bernhard Koniszewski and Martin Kollmann contributed equally to this work.

Electronic supplementary material The online version of this article (doi:10.1007/s00427-016-0542-7) contains supplementary material, which is available to authorized users.

Gregor Bucher

gbucher1@uni-goettingen.de

1 Department of Evolutionary Developmental Genetics, Johann-Friedrich-Blumenbach Institute, GZMB, CNMPB, Georg-August-University Göttingen, Göttingen Campus, Göttingen, Germany

2 Institute of Medical Microbiology, Otto-von-Guericke-University, Magdeburg, Germany

3 Department of Biology, Animal Physiology, Philipps-University, Marburg, Germany

4 Department of Biology, Neurobiology, University of Konstanz, Constance, Germany mark homologous neural cells in the fly D. melanogaster, the beetle Tribolium castaneum, and the Mediterranean field cricket Gryllus bimaculatus to investigate developmental differences leading to brain diversification. One interesting aspect is the heterochrony observed in central complex development. Ancestrally, the central complex is formed during embryogenesis (as in Gryllus) but in Drosophila, it arises during late larval and metamorphic stages. In Tribolium, it forms partially during embryogenesis. Finally, we present tools for brain research in Tribolium including 3D reconstruction and immunohistochemistry data of first instar brains and the generation of transgenic brain imaging lines. Further, we characterize reporter lines labeling the mushroom bodies and reflecting the expression of the neuroblast marker gene $T c$-asense, respectively.

Keywords Central complex · Brain · Heterochrony · Evolution $\cdot$ Tribolium $\cdot$ Drosophila

\section{Diversity of adult brain morphology and developmental timing}

The insect brain: morphological diversity based on a conserved architecture

The brain integrates sensory inputs, internal states, and other information to produce a specific behavioral pattern. Due to this essential role for survival, brain morphology and function are likely to be under high selective pressure. Indeed, the basic architecture of the insect brain is highly conserved and the different neuropils that serve particular functions are found in similar spatial arrangement in most adult insect species (Fig. 1) (Holmgren 1916; Hanström 1928; Snodgrass 1935; Weber 1966; Strausfeld 1976, 2005; Rein et al. 2002; Schachtner et al. 2005; Brandt et al. 2005; Kurylas et al. 2008; Homberg 2008; 

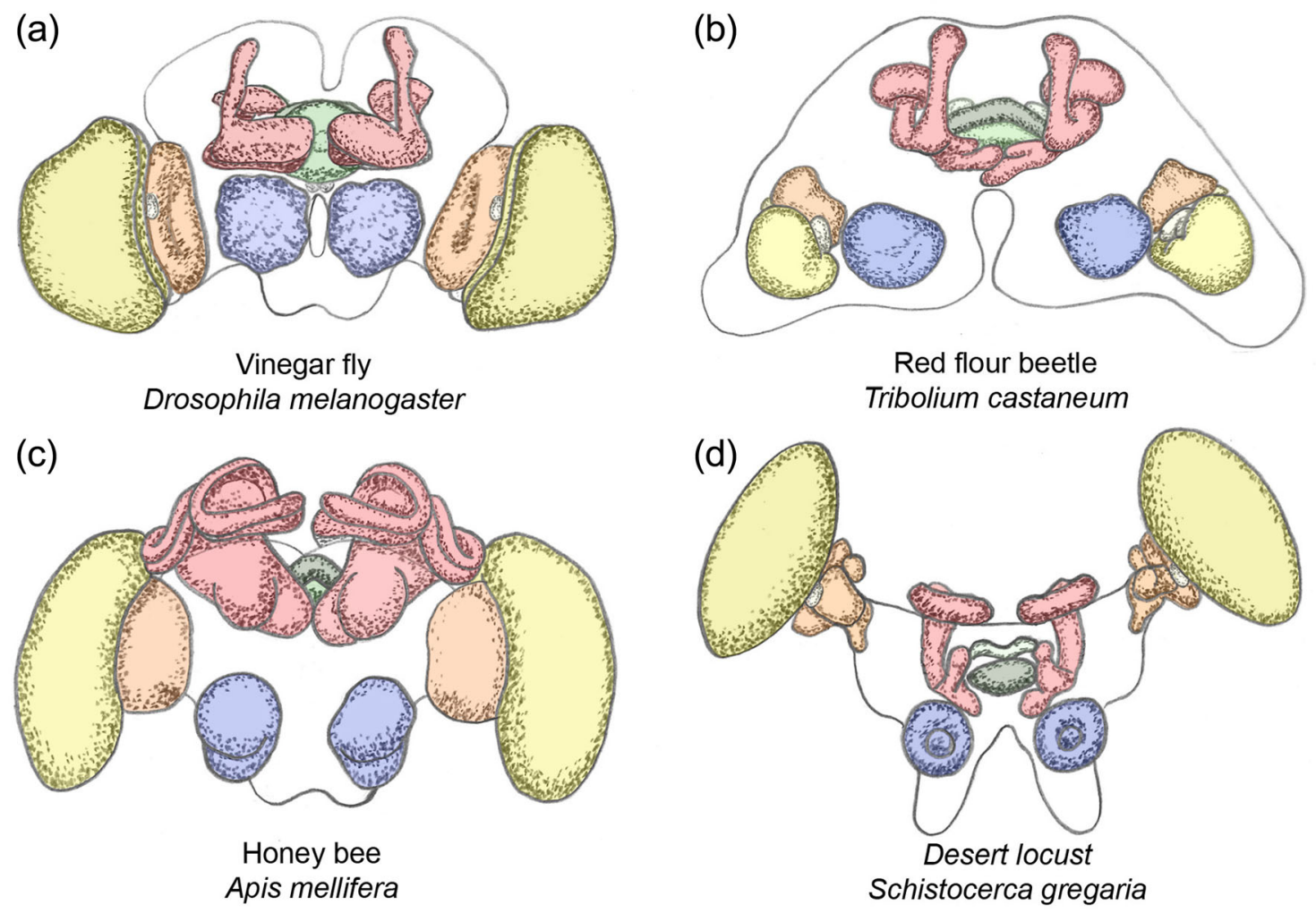

Fig. 1 Diversity of adult insect brains. Shown are illustrations of the brains of the vinegar fly Drosophila melanogaster (a), the red flour beetle Tribolium castaneum (b), the bee Apis mellifera (c), and the desert locust Schistocerca gregaria (d). Based on (Rein et al. 2002;

El Jundi et al. 2009a, b; Strausfeld et al. 2009; Dreyer et al. 2010). However, size and shape as well as timing of the development of the neuropils differ between insects. For example, 3D reconstructions of several insect brains revealed that the mushroom bodies of bees required for learning and memory have a large volume as compared to Drosophila and Tribolium (Brandt et al. 2005). Compared to the vinegar fly, the optic lobes (OLs) of the red flour beetle are small while its antennal lobes (ALs) are large (Dreyer et al. 2010). The combined relative volume of the central complex (CX) neuropils is larger in Tribolium as compared to Drosophila (for simplicity, we use the genus name of the model systems) (Rein et al. 2002; Brandt et al. 2005; Kurylas et al. 2008; El Jundi et al. 2009a; Dreyer et al. 2010). Interestingly, also, the timing of neuropil development varies. For instance, the CX is fully formed during embryogenesis in orthopteran insects while it develops postembryonically in flies. However, almost nothing is known about the genetic and cellular mechanisms that underlie the development of differences in morphology or developmental timing of neuropils between species. In this perspective paper, we present a novel developmental genetics approach to studying the development of homologous brain centers in different insect species. This approach has the power to reveal the cellular and genetic basis of insect brain diversification.

Kurylas et al. 2008; Dreyer et al. 2010; Rybak et al. 2010). All brains were sized to the same width and the respective neuropils have the same color code: blue antennal lobes, red mushroom bodies, yellow lamina of optic lobes, orange lobula of optic lobes, green central complex

\section{The conserved developmental basis: neural lineages and genetic control}

The genetic mechanisms underlying insect neural development have been studied most extensively in the vinegar fly Drosophila melanogaster and appear to be similar in other insects (Campos-Ortega and Hartenstein 1985; Skeath and Thor 2003; Urbach and Technau 2004; Brody and Odenwald 2005; Technau et al. 2006; Hartenstein et al. 2008; Egger et al. 2008). The developmental units that build the brain are neural lineages, which consist of one neuroblast (neural stem cell) and all its daughter cells, which can be either neurons or glia. The cell bodies of a given lineage stay together and the projection patterns of all daughter neurons are usually similar (Technau et al. 2006; Spindler and Hartenstein 2010; Pereanu et al. 2011; Boyan and Reichert 2011). In type I neuroblasts, asymmetric divisions produce several ganglion mother cells (GMCs), each of which divides once more to form postmitotic cells. Type II neuroblasts generate transit amplifying progenitors (TA-GMC; also called intermediate neural progenitors INP), which themselves divide in a stem cell mode giving rise to GMCs (Bello et al. 2008; 
Bowman et al. 2008; Boone and Doe 2008). Hence, many more daughter cells are produced per type II neuroblast. For instance, the Drosophila CX is formed from both types of neuroblasts (Bayraktar et al. 2010; Viktorin et al. 2011). Neural lineage development is not necessarily a continuous process. After an initial embryonic phase of division, many Drosophila neuroblasts enter quiescence for an extended period of time and resume proliferation at a later developmental stage (Egger et al. 2008).

Many aspects of cellular and genetic bases of neural development are conserved in animals (Denes et al. 2007; Hartenstein and Stollewerk 2015). In particular, the gene networks involved in specifying neural precursors and their spatial identity are highly conserved in insects and partly even in other arthropods (Wheeler et al. 2005; Stollewerk and Simpson 2005; Eriksson and Stollewerk 2010; Biffar and Stollewerk 2014; Stollewerk 2016). Homology of neural lineages has been suggested based on Crustacean neuroblasts, which show a comparable spatial arrangement, timing of delamination, transcription factor expression, and projection patterns as their insect counterparts (Ungerer and Scholtz 2008). Other examples are the similar location and the ongoing divisions of MB neuroblasts and the existence of type II neuroblasts at a comparable position and their contributions to the $\mathrm{CX}$ in a grasshopper (Boyan et al. 2010b; Boyan and Reichert 2011). In summary, at least the early development of the nervous system appears to be highly conserved.

\section{The question}

The diversity of neuropil morphology and instances of heterochrony in brain development are well documented in a plethora of species. These differences between species must have evolved by modifications of the embryonic and postembryonic developmental programs. However, the nature of the changes of cellular and genetic mechanisms remains unknown. In part, this may be due to the fact that for technical reasons, developmental genetic studies have been largely restricted to Drosophila for a long time. We propose that the emerging tools for functional genetics outside Drosophila will allow comparing developmental mechanism between species.

\section{The concept: genome editing allows the genetic marking of homologous cells}

In order to identify the differences in development between species, small groups of homologous cells need to be compared throughout development in both species, i.e., from the embryonic neuroblast to its progeny in the adult brain. There are several antibodies that allow marking for instance of serotonin-positive cells in different species. However, these markers do not mark neuroblasts or other neural progenitors during early phases of brain development. Furthermore, it has remained challenging even in Drosophila to mark a given lineage from the nascent neuroblast onwards and extensive enhancer trap collections marking subsets of neural cells are available only in Drosophila.

The recent development of genome editing tools changes the game because they have the potential to allow the genetic marking of groups of cells, which can be traced from neuroblast to the adult brain. By marking homologous cells in different taxa, the cellular basis of different developmental paths can be studied. We propose to establish such tools in a two-step process. First, groups of cells are genetically marked by their virtue of expressing a conserved transcription factor. Several transcription factors remain detectable in a certain lineage from the delaminating neuroblast to at least a subset of daughter cells of that neuroblast like engrailed (Kumar et al. 2009), and Ct, Dan, Dll, and Optix in type II neuroblasts (Bayraktar and Doe 2013). By genome editing, enhancer trap constructs encoding fluorescent protein can be integrated into the locus of such a neuroblast marker gene. The regulatory elements of that gene will drive expression of the fluorescent protein in all cells which express the gene. Transcription factors that are likely to be relevant should (1) be active in restricted regions in the neuroectoderm, (2) remain expressed in postmitotic neural cells of the brain, (3) be highly conserved in anterior brain development in bilaterians, and (4) their function should be required for the formation of the brain structure under study. Previous work identified good candidates: We and others showed that a set of conserved genes is required for patterning both vertebrate neural plate and invertebrate neuroectoderm (Lowe et al. 2003; Denes et al. 2007; Steinmetz et al. 2010; Posnien et al. 2011) and at least some of them were active in neural cells of the brain making them excellent candidates for marking homologous cells (Posnien et al. 2011).

In a second step, homology of marked cells needs to be corroborated by comparing location of marked cell bodies, projection patterns, neuromodulator content, and other features. A similar reasoning provided the basis of previous efforts to identify homologous neural cells based on molecular similarity (Urbach and Technau 2003; Arendt 2005; Tomer et al. 2010; Biffar and Stollewerk 2014). In addition, the assumed continuous expression from neuroblasts to the postmitotic cells will have to be shown for each reporter. The methods outlined here should be applicable to study the stage and the nature of developmental changes that lead to different morphologies or to differences in developmental timing. In the following, we describe an intriguing case of heterochronic development, which could be studied using this approach. 


\section{The central complex as a model for studying brain evolution}

\section{The central complex - a higher order integration center of the brain}

We propose that the insect central complex (CX) is an excellent case to study heterochrony as one aspect of evolutionary adaptation of the brain. Before doing so, we briefly introduce to morphology and function of this neuropil-please refer to the recent review by Pfeiffer and Homberg for original work (2014). Apart from the paired noduli, the insect central complex (CX) typically consists of a set of unpaired neuropils spanning the midline (i.e., the protocerebral bridge (PB), central body $(\mathrm{CB})$ with upper and lower unit, also called fanshaped body (FB) and ellipsoid body (EB)) (Fig. 2a-c). The paired lateral accessory lobes (LAL) are not part of the CX but they are considered as strongly associated to the CX (Homberg 2008). The wiring scheme within and between these neuropils is highly ordered and reflects their organization in columns and layers. For instance, tangential neurons connect the columns within one neuropil while columnar neurons connect specific columns of different neuropils with each other while other neurons connect the CX to other brain parts (Power 1943; Williams 1975; Strausfeld 1976; Homberg 1985, 2008; Hanesch et al. 1989; Loesel et al. 2002; Boyan and Williams 2011; Pfeiffer and Homberg 2014). Among other higher order brain functions, the CX is involved in sky compass orientation, locomotor behavior, courtship, and memory among others (Strauss 2002; Homberg 2008; Pfeiffer and Homberg 2014; Heinze 2015). Similar midline neuropils have been found in many Arthropoda including Collembolans, Crustacea, Chelicerata, Myriapoda, and even Onychophora (Loesel et al. 2002; Strausfeld et al. 2006; Kollmann et al. 2011), and homology of the CX with the vertebrate basal ganglia has been suggested (Strausfeld and Hirth 2013). The function of the CX has become a major focus of neurobiology research and extensive imaging and misexpression resources are being generated (Hanesch et al. 1989; Loesel et al. 2002; Pfeiffer et al. 2008; Cardona et al. 2010; Young and Armstrong 2010a, b; Jenett et al. 2012; Takemura et al. 2013; Ito et al. 2014). Several neural lineages contributing to the CX were found but the embryonic part of their development remains poorly studied (Renn et al. 1999; Young and Armstrong 2010a, b; Pereanu et al. 2011; Riebli et al. 2013; Yang et al. 2013).

\section{Heterochronic development of the central body}

An intriguing divergence was observed regarding the timing of CX development, which was comprehensively described for the CB (Hanström 1925; Panov 1959; Wegerhoff and Breidbach 1992; Boyan and Williams 1997, 2011; Loesel et al. 2002; Boyan and Reichert 2011). In most hemimetabolous insects, the $\mathrm{CB}$ develops fully during embryogenesis. During postembryonic development, the $\mathrm{CB}$ just grows in size (a)

(d)

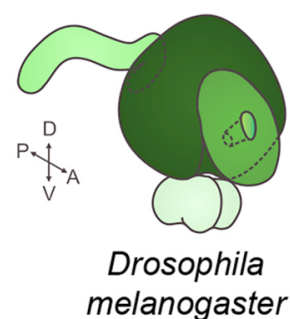

embryonic

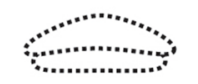

post-
embryonic

adult

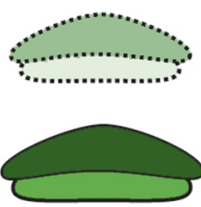

Fig. 2 Heterochronic development of the central complex. a-d The central complex of adult specimen of the vinegar fly Drosophila melanogaster (a), the red flour beetle Tribolium castaneum (b), and the desert locust Schistocerca gregaria (c) are shown sized to the same width. Note that the overall architecture of the CX components is similar as is their basic connectivity (not depicted). Central body with fan-shaped body $(F B)$ and ellipsoid body $(E B)$. No noduli; $P B$ protocerebral bridge. d Heterochronic development of the $\mathrm{CB}$ is depicted schematically for the species $(\mathbf{a}-\mathbf{c})$. This neuropil is fully

(b)
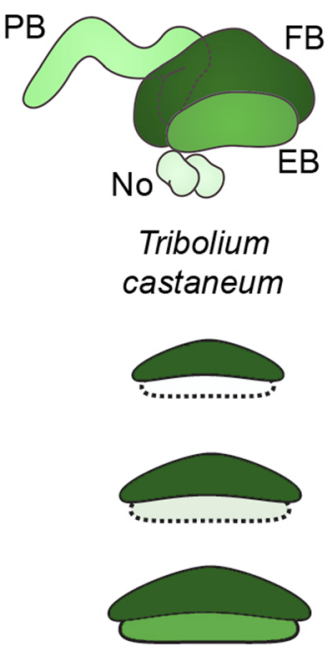

(c)
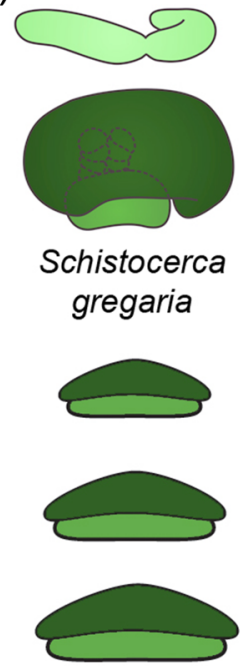

developed in desert locust hatchlings, representing the ancestral condition. In the beetle, only the FB (dark green) is present while the EB (light green) is added postembryonically. In the vinegar fly, the neuropil becomes apparent only at late larval and metamorphic stages. Light colors and hatched outlines mark neuropils that are developing but not yet functional while white indicates lack of detectable neuropil structure. Note that neuropil shapes are unified and other CX neuropils have been omitted for simplicity. a-d Redrawn from (Hanesch et al. 1989; Dreyer et al. 2010; Kaiser 2014) 
with minor morphological changes. This has been shown for several orthopteran taxa including crickets (Gryllus, Metrioptera), grasshoppers (Calliptamus, Schistocerca), mantids (Ameles), and stick insects (Dixippus-now Carausius). Likewise, this has been found in hemipteran bugs (Palomena). By contrast, a CB neuropil is morphologically not detectable in hatchlings of some butterflies and moths (Pieris, Ephestia), mayflies (Ephemera), hymenoptera (Apis), and flies (Musca, Drosophila) (Panov 1959). However, in Drosophila first instar larva, some commissural tracts prefigure the location of the later CB (Hinke 1961; Riebli et al. 2013). A partial CB, namely the FB, was found in hatchlings of some Neuroptera (Chrysopa, Ascalaphus), Lepidoptera (Antheraea, Manduca), and a Diptera (Culex) (Panov 1959; Homberg and Hildebrand 1994). Within beetles, there are species where hatchlings do not yet display a CB like the curculionid Anthonomus or Oryctes (Jawlowski 1936) while a partial CB was detected in tenebrionid beetles (Tenebrio molitor, Tribolium castaneum) (Wegerhoff and Breidbach 1992; Wegerhoff et al. 1996; this work). The partial $\mathrm{CB}$ present in hatchlings usually represents the fan-shaped body. In summary, the timing of CB development has repeatedly been shifted relative to overall development of the animal during insect evolution with the full embryonic development probably being ancestral. Such evolutionary shifts of developmental timing have been termed "heterochrony" (Gould 1977). The different times of CB emergence within insect families like flies and beetles indicates that heterochrony has evolved several times. The functional relevance remains speculative: Most species where hatchlings lack a CB show no or only a poorly developed visual system (Panov 1959) and the embryonic development of the CX coincides with the emergence of walking legs - the legs are fully developed in hatchlings of hemimetabolous insects while tenebrionid larvae have reduced legs and Drosophila larvae do not have any legs (Pfeiffer and Homberg 2014).

\section{Cricket, beetle, and fly as model systems to study the genetic basis of brain evolution}

What insect model systems are likely to be most useful for research on the functional genetics of brain evolution? Of course, these model systems need to represent clear evolutionary changes of neuropil size, shape, or timing of development but they need to be amenable to functional genetics as well. Given these demands, the cricket Gryllus bimaculatus, the vinegar fly $D$. melanogaster, and the red flour beetle T. castaneum form an excellent group of model organisms. Functional genetic tools within orthopterans are best developed in the cricket Gryllus with RNAi and transgenesis established and it represents the ancestral state of CX development (Fig. 2d) (Panov 1959; Miyawaki et al. 2004;
Nakamura et al. 2010; Zeng et al. 2013; Watanabe et al. 2014). Cellular development of the ancestral state of the CX has been described best in the orthopteran Schistocerca gregaria (Boyan et al. 2003, Boyan et al. 2010a, b; Williams et al. 2005; Boyan and Reichert 2011; Boyan and Williams 2011; Boyan and Liu 2014). However, due to their close phylogenetic relationship, it is likely that most knowledge gained in S. gregaria will be transferrable to G. bimaculatus.

Tenebrionid beetles represent the intermediate state where the FB forms during embryogenesis. It is only during the pupal stage that the ellipsoid body is eventually completed (Wegerhoff and Breidbach 1992; Wegerhoff et al. 1996) (Fig. 2d). Importantly, with respect to functional genetics, the red flour beetle Tribolium is second only to Drosophila including transgenesis, large-scale enhancer trap screen, misexpression tools, and in vivo imaging lines (Berghammer et al. 1999; Lorenzen et al. 2003; Trauner et al. 2009; Schinko et al. 2010; Posnien et al. 2011; Schinko et al. 2012; Sarrazin et al. 2012). RNAi-mediated gene knockdown is strong and is either environmental or systemic. Hence, when dsRNA is injected into the hemolymph, the knockdown spreads to reach all cells of the injected animal and is even transmitted to the offspring of injected females (Brown et al. 1999; Curtis et al. 2001; Bucher et al. 2002; Tomoyasu and Denell 2004; Miller et al. 2012; Peel et al. 2013). Mutant phenotypes were described for Tc-knirps, Tc-Distal-less, and Tc-sex combs reduced and in all these cases, RNAi phenocopied the null phenotype. Resources for large-scale RNAi screening are being established with currently half of the genome being covered by dsRNA templates (Dönitz et al. 2015; Schmitt-Engel et al. 2015). Finally, the CRISPR/Cas9 system has been established (Gilles et al. 2015).

Drosophila represents the most derived state of CX morphology, with the $\mathrm{CX}$ anlagen of the hatchling consisting of commissural tracts lacking neuropil morphology and synapses indicating non-functionality (Fig. 2d). Only during late larval stages and metamorphosis, the CX neuropils develop and mature (Renn et al. 1999; Young and Armstrong 2010a; Pereanu et al. 2011; Riebli et al. 2013; Pfeiffer and Homberg 2014). Drosophila is the prime model system for insect functional genetics with an excellent toolkit. Due to the delayed development in the fly, research on $\mathrm{CX}$ formation is focusing on the postembryonic phase (Viktorin et al. 2011; Jiang and Reichert 2012; Carney et al. 2012; Bayraktar and Doe 2013; Yang et al. 2013).

\section{Studying brain development in the red flour beetle}

\section{Immunohistochemistry confirms presence of one central body neuropil in the $\mathrm{L} 1$ larval brain}

Tribolium is a useful model for CX development for two reasons: first, it allows studying the embryonic aspects of $\mathrm{CX}$ 
development. Second, comparison to Drosophila will reveal the cellular and genetic basis of the heterochronic shift between these species. In order to establish Tribolium as a model system for CX development, we first studied the L1 brain morphology by immunohistochemistry targeting synapsin followed by 3D reconstruction (Fig. 3; see Online Resource
S1 for methods). We found the upper division of the central body (FB; dark green in Fig. 3a-g) with a flattened bar-like shape. An EB was not found at that stage. These data are in line with findings in T. molitor where the larval $\mathrm{CB}$ was described to consist of the FB only. The PB (Fig. 3b, e-g; light green) was present but medially split, probably
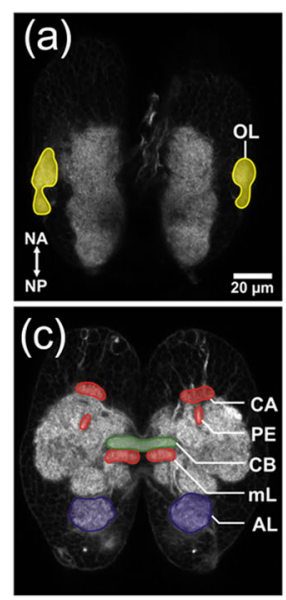

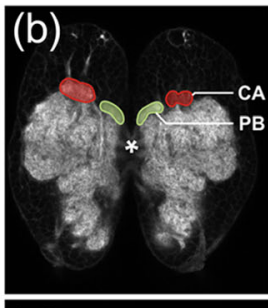

(d)

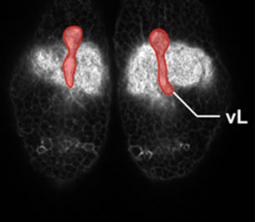

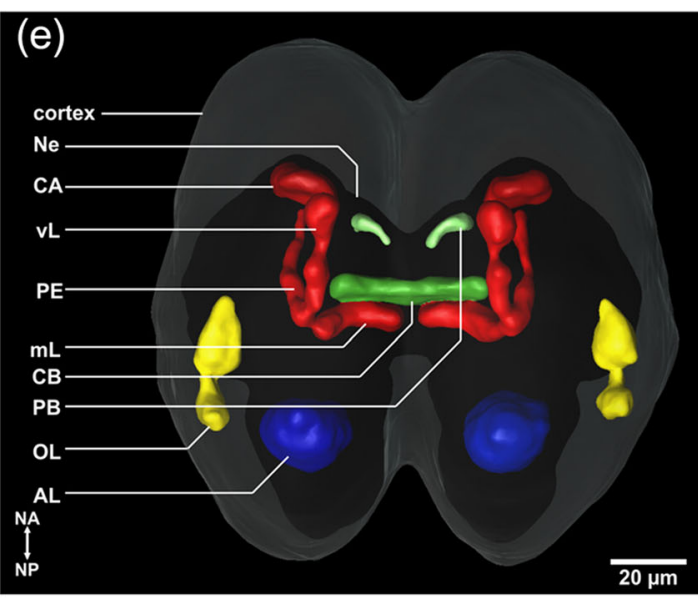
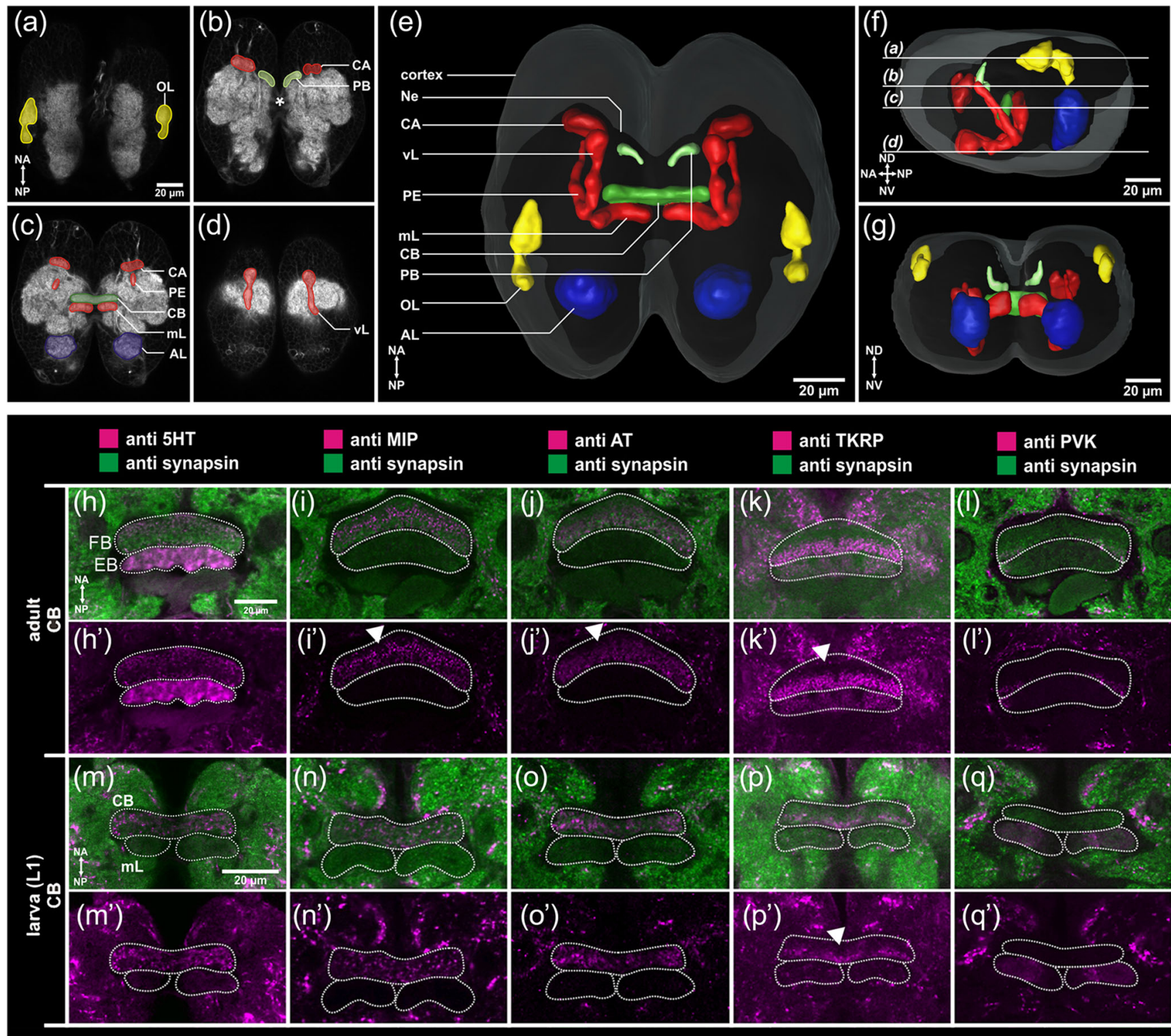

(o')
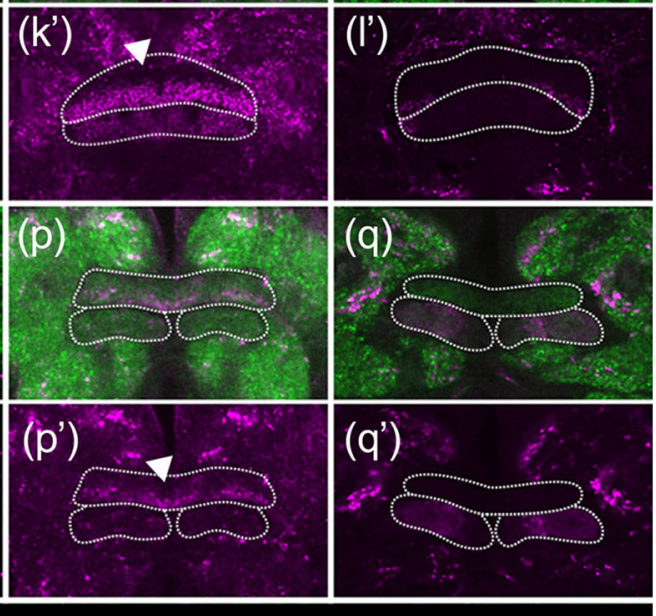

Fig. 3 The first instar larval brain of Tribolium castaneum and expression of neuromodulators in the CB. a-d Dorsal view of a first instar larval brain stained with an antibody detecting synapsin. The level of the sections is displayed in the reconstruction (f). e- $\mathbf{g} 3 \mathrm{D}$ reconstruction of neuropils based on the synapsin staining (a-d). Color code: blue antennal lobes $(A L)$, yellow (anlagen of the) optic lobes $(O L)$, and red mushroom bodies $(M B)$ with calyx $(C A)$; $P E$ pedunculus, $v L$ vertical lobe, and $m L$ medial lobe. The cortex layer containing most cell bodies is shown in light gray, while the entire neuropilar mass of the brain is shown in dark gray $(\mathrm{Ne})$. $\mathbf{h}-\mathbf{q}$ Optical sections through the $\mathrm{CB}$ in adults $(\mathbf{h}, \mathbf{l})$ and first instar larvae $(\mathbf{m}, \mathbf{q})$ stained against serotonin $(5 H T)$,

myoinhibitory protein $(M I P)$, allatotropin $(A T)$, tachykinin-related peptide $(T K R P)$, and periviscerokinin $(P V K)$. Neural anterior (n-anterior; $N A$ ) is up in all panels. $F B$ fan-shaped body, $E B$ ellipsoid body. The staining in the larval $\mathrm{CB}$ resembles staining of the FB in adult brains, corroborating the previous assumption that only the FB develops during embryogenesis. The anterior rim of the adult FB lacks MIP and AT expression (white arrowheads in $i$ and $j$ ), which is not the case in larval CB. An n-anterior lack of TKRP reactivity, in contrast, is found in both larval and adult brains (white arrowhead in $k$ and $p$ ). Scale- and orientation bars (a) account for (b-d), bars (h, m) account for $i-l, n-q$, $h-l$, and $m-q$ 
with some fibers connecting both parts (Fig. 3b; asterisk). Only during later larval development these two parts fuse (not shown). Interestingly, a PB was not detected in hatchlings of T. molitor but a split PB emerged at later larval stages before it fuses during metamorphosis (Wegerhoff and Breidbach 1992; Wegerhoff et al. 1996). Whether this reflects a heterochronic shift within Tenebrionidae or is due to different sensitivity of the methods used remains to be tested. We did detect no noduli in L1 larval brains.

Using immunohistochemistry, we found the biogenic amine serotonin (5HT) as well as the neuropeptides myoinhibitory peptide (MIP), allatotropin (AT), and tachykinin-related peptide (TKRP) in both the adult FB and the L1 CB. The neuropeptide periviscerokinin (PVK) was absent in the adult and larval CBs (compare Fig. 3h-k with $\mathrm{h}-\mathrm{k}$; see Online Resource 1 for more detailed description and Fig. S1 in Online Resource 2 for comparison of other neuropils and Online Resources 3-14 for confocal stacks of adult and embryonic brains) (Wegerhoff and Breidbach 1992). Curiously, the nanterior rim of the adult FB lacks MIP and AT immunoreactivity (white arrowheads in Fig. $3 i$ and $j$ ) while in the larval $\mathrm{CB}$, a correspondingly unstained rim was not found. In case of TKRP, n-anterior immunoreactivity lacked in both adult and larval CB (white arrowheads in Fig. $3 \mathrm{k}$ and $\mathrm{p}$ ). The expression of synapsin and neuromodulators in the $\mathrm{CB}$ strongly indicates that the neuropil is functional in the hatchling already. As proof of principle, we tested several stainings in Tc-six 3 RNAi-knockdown animals, where CB deletion had previously been described (Posnien et al. 2011). The brains of L1 larvae were dissected and the previously published MB phenotype was confirmed by immunohistochemistry using the DC0 antibody (see Fig. S3 in Online Resource 2). Immunohistochemistry in Tc-six3 RNAi-knockdown animals against DC0, 5HT, and MIP showed a specific signal in the brain as in wild type but the signal corresponding to the $\mathrm{CB}$ was not found confirming our previous data (see Fig. S3 in Online Resource 2).

To increase the repertoire of neural markers in Tribolium, we tested a number antibodies used in Drosophila research but most of them showed no or inconsistent signal (see Online Resource 16 for complete list). However, only the antibodies targeting reversed polarity (a marker for glia), aPKC, Bazooka (both asymmetrically loalized in neuroblasts), even skipped, engrailed (markers for subsets of neuroblasts and neurons), fasciclin 2 (marker for subsets of axons), death caspase 1 (marker for apoptosis), and phosphohistone-3 (marker for dividing cells) were confirmed to cross-react.
Transgenic lines marking the mushroom bodies and reporting asense expression

For the analysis of cell body location and projection patterns in wild-type and knockdown phenotypes, it is advantageous to have transgenic lines that mark specific subsets of neural cells or certain neuropils. From a previous enhancer trap screen (Trauner et al. 2009), we identified the line G11410 which marked the mushroom bodies with enhanced green fluorescent protein (EGFP) ("MB-green") (Fig. S2 in Online Resource 2) (Posnien et al. 2011; Binzer et al. 2014). Colocalization of EGFP with DC0 in the neuropil confirmed that MB was marked (Skoulakis et al. 1993; Farris and Strausfeld 2003) (Fig. S2 in Online Resource 2). In order to mark neuroblasts (NBs), we used an intronic fragment of the NB marker Tc-asense (see Online Resource 1 for sequence) to drive Gal4delta ("ase-Gal4") (Wheeler et al. 2003). Indeed, when crossed with the UAS-tGFP line, fluorescence was detected in the ventral nerve cord and the brain of late embryos (not shown). Double in situ hybridization confirmed co-expression of Gal4delta and Tc-asense (Fig. 4a, b).

\section{Reporter lines for neural and glial cells allow in vivo imaging of brain development}

We wanted to generate imaging lines marking neural cell types. An artificial promoter containing three eyless/Pax6 binding sites (3XP3) and the Drosophila heat-shock core promoter drove EGFP in the eyes in a wide range of animals (Sheng et al. 1997; Berghammer et al. 1999). However, recent work indicated that 3 XP3 reports the expression of the homeobox gene Pph13 rather than the eyeless/Pax6 (Mishra et al. 2010). In Tribolium, we noted additional fluorescent signal in the brain with variable intensity. To render this signal more robust, we generated transgenic lines where six copies of the P3 elements (6XP3) drove either enhanced cyan fluorescent protein (ECFP) or dsRed-Express from the Tribolium hsp68 core promoter. Both constructs led to a specific signal in glial cells (Posnien et al. 2011). The respective lines were called "glia-blue" and "glia-red." To determine the portion of marked glia, we tested for colocalization with the glia marker reverse polarity (4 $\alpha 3$, Repo) (Fig. S2 in Online Resource 2) (Xiong et al. 1994). We found a large degree of co-expression in the nuclei of glia cells while the reporter additionally visualized the cell bodies. Quantification (excluding the OL) revealed that about 608 glial cells were marked by the Repo antibody $(n=5 ; \mathrm{SD}=64 ; \mathrm{SE}=32)$ with about $524(86 \%)$ of them being positive for the ECFP signal as well $(n=5 ; \mathrm{SD}=47.5 ; \mathrm{SE}=23.8)$. About eight ECFP- 

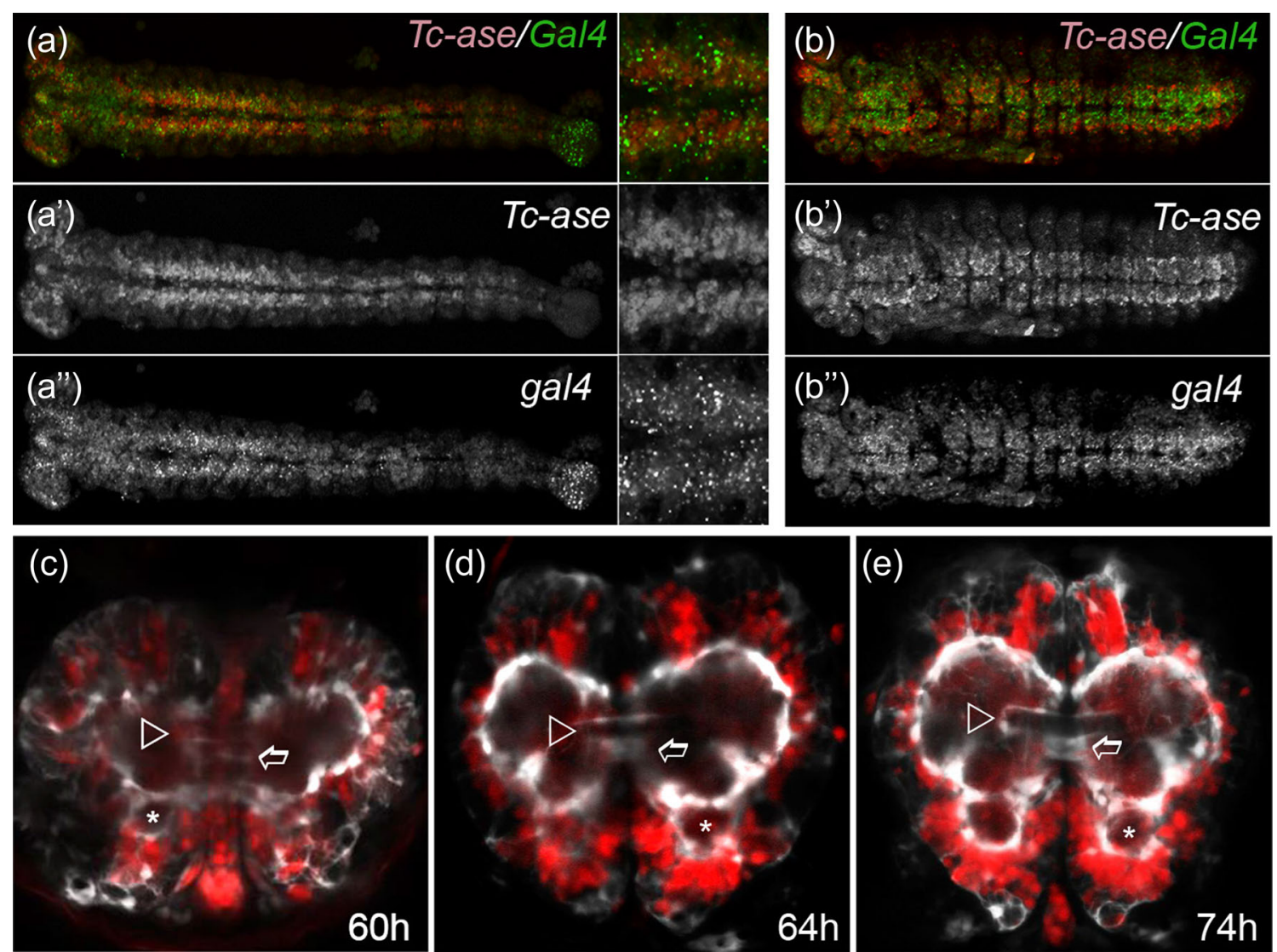

Fig. 4 Transgenic in vivo imaging reporters for brain research in Tribolium castaneum. a, b The regulatory region of Tc-asense drives expression of Gal4 in neuroblasts. The overlap of expression was confirmed with double in situ hybridization detecting Tc-ase (red) and gal4 (green). a-a" mid-embryogenesis; b-b" late embryogenesis. $\mathbf{c}-\mathbf{e}$ Developmental series of the fluorescence signal of the brainy line. The ECFP signal marking glia is shown in white while the DsRed-Express

signal in neurons is depicted in red. Embryos are oriented n-anterior to the top. White arrowhead marks the developing central body; stars indicate the antennal lobes while open arrows mark the median lobes of the mushroom bodies. d, e The glial sheath of the central body is first detected in 60-64-h-old embryos and is clearly visible in brains of hatchlings (e). See Online Fig. S2 in Resource 2 for earlier stages

positive cells $(1.5 \%)$ did not show Repo staining $(n=5$; $\mathrm{SD}=2.9 ; \mathrm{SE}=14)$. These could be glia of mesectodermal origin, which are Repo negative, at least in Drosophila (Parker and Auld 2006).

"Neuron-red" is a transgenic line where the upstream region of one of the Tc-EF1-alphaB paralogs unexpectedly drove DsRed-Express in neurons (Averof, personal communication; see Online Resource 1 for sequence) (Posnien et al. 2011). To monitor both glia and neurons in the same animal, we crossed the glia-blue and neuron-red lines establishing the "brainy" line (Fig. 4 and Fig. S2 in Online Resource 2; glia in white, neurons in red) (Posnien et al. 2011). To test the suitability for in vivo imaging, we monitored both signals in living embryos. Expression of ECFP was first detected in 17-h-old embryos $\left(32{ }^{\circ} \mathrm{C}\right)$ while first expression of DsRedEx became detectable at $24 \mathrm{~h}$ (Fig. S2 in Online Resource 2). Strong branching of glia was observed in 40-h-old embryos. First signs of the CB were detected from $55 \mathrm{~h}$ onwards (open arrowhead in Fig. 4c-e). Antennal lobes (AL) and the median lobes of the mushroom bodies (mL) were detected from $60 \mathrm{~h}$ onwards (asterisks and open arrow in Fig. 4c-e, respectively).

\section{Conclusion}

The cellular and genetic mechanisms of the evolution of the tremendous diversity of neuropil morphology remain enigmatic. Using the models, concepts, and tools presented in this work, it will be possible to study this fascinating question. Further, we believe that the central complex is an excellent model system to study heterochrony as one aspect of brain evolution and we present tools that will turn out to be useful for the study of this and additional questions regarding the brain development of Tribolium. 
Acknowledgments We thank Michalis Averof for the transgenic "neuron-red" line and Uwe Homberg for providing the 3D data stacks for the generation of the schematic of the CX of $S$. gregaria. NDBK was funded by the DFG Research Center "Molecular Physiology of the Brain" (CMPB).

Author contributions NDBK, MBig, and MBü generated and analyzed transgenic lines. MK established and analyzed stainings of the wild-type larval brain. WH and MBin contributed stainings of the adult brain. NDBK analyzed the RNAi knockdown. NDBK, MK, JS, MF, BH, and MBü contributed to the concept and the writing of the manuscript. GB designed the study and wrote the manuscript. All authors read and approved of the manuscript.

Open Access This article is distributed under the terms of the Creative Commons Attribution 4.0 International License (http:// creativecommons.org/licenses/by/4.0/), which permits unrestricted use, distribution, and reproduction in any medium, provided you give appropriate credit to the original author(s) and the source, provide a link to the Creative Commons license, and indicate if changes were made.

\section{References}

Arendt D (2005) Genes and homology in nervous system evolution: comparing gene functions, expression patterns, and cell type molecular fingerprints. Theory Biosci 124:185-197

Bayraktar OA, Doe CQ (2013) Combinatorial temporal patterning in progenitors expands neural diversity. Nature 498:449-455. doi:10. 1038/nature12266

Bayraktar O, Boone JQ, Drummond ML, Doe CQ (2010) Drosophila type II neuroblast lineages keep Prospero levels low to generate large clones that contribute to the adult brain central complex. Neural Dev 5:26. doi:10.1186/1749-8104-5-26

Bello BC, Izergina N, Caussinus E, Reichert H (2008) Amplification of neural stem cell proliferation by intermediate progenitor cells in Drosophila brain development. Neural Dev 3:5. doi:10.1186/17498104-3-5

Berghammer AJ, Klingler M, Wimmer EA (1999) A universal marker for transgenic insects. Nature 402:370-371

Biffar L, Stollewerk A (2014) Conservation and evolutionary modifications of neuroblast expression patterns in insects. Dev Biol 388:103116. doi:10.1016/j.ydbio.2014.01.028

Binzer M, Heuer CM, Kollmann M et al (2014) Neuropeptidome of Tribolium castaneum antennal lobes and mushroom bodies. J Comp Neurol 522:337-357. doi:10.1002/cne.23399

Boone JQ, Doe CQ (2008) Identification of Drosophila type II neuroblast lineages containing transit amplifying ganglion mother cells. Dev Neurobiol 68:1185-1195. doi:10.1002/dneu.20648

Bowman SK, Rolland V, Betschinger J et al (2008) The tumor suppressors brat and numb regulate transit-amplifying neuroblast lineages in Drosophila. Dev Cell 14:535-546. doi:10.1016/j. devcel.2008.03.004

Boyan G, Liu Y (2014) Timelines in the insect brain: fates of identified neural stem cells generating the central complex in the grasshopper Schistocerca gregaria. Dev Genes Evol 224:37-51. doi:10.1007/ s00427-013-0462-8

Boyan GS, Reichert H (2011) Mechanisms for complexity in the brain: generating the insect central complex. Trends Neurosci 34:247-257. doi:10.1016/j.tins.2011.02.002

Boyan GS, Williams JLD (1997) Embryonic development of the pars intercerebralis/central complex of the grasshopper. Dev Genes Evol 207:317-329. doi:10.1007/s004270050119
Boyan G, Williams L (2011) Embryonic development of the insect central complex: insights from lineages in the grasshopper and Drosophila. Arthropod Struct Dev 40:334-348. doi:10.1016/j.asd. 2011.02.005

Boyan GS, Bräunig P, Posser S, Williams JLD (2003) Embryonic development of the sensory innervation of the clypeo-labral complex: further support for serially homologous appendages in the locust. Arthropod Struct Dev 32:289-302

Boyan G, Herbert Z, Williams L (2010a) Cell death shapes embryonic lineages of the central complex in the grasshopper Schistocerca gregaria. J Morphol 271:949-959. doi:10.1002/jmor.10847

Boyan G, Williams L, Legl A, Herbert Z (2010b) Proliferative cell types in embryonic lineages of the central complex of the grasshopper Schistocerca gregaria. Cell Tissue Res 341:259-277. doi:10.1007/ s00441-010-0992-6

Brandt R, Rohlfing T, Rybak J et al (2005) Three-dimensional averageshape atlas of the honeybee brain and its applications. J Comp Neurol 492:1-19. doi:10.1002/cne.20644

Brody T, Odenwald WF (2005) Regulation of temporal identities during Drosophila neuroblast lineage development. Curr Opin Cell Biol 17: 672-675. doi:10.1016/j.ceb.2005.09.013

Brown SJ, Mahaffey JP, Lorenzen MD et al (1999) Using RNAi to investigate orthologous homeotic gene function during development of distantly related insects. Evol Dev 1:11-15

Bucher G, Scholten J, Klingler M (2002) Parental RNAi in Tribolium (Coleoptera). Curr Biol 12:R85-R86

Campos-Ortega JA, Hartenstein V (1985) The embryonic development of Drosophila melanogaster. Springer, New York

Cardona A, Saalfeld S, Preibisch S et al (2010) An integrated micro- and macroarchitectural analysis of the Drosophila brain by computerassisted serial section electron microscopy. PLoS Biol. doi:10. 1371/journal.pbio.1000502

Carney TD, Miller MR, Robinson KJ et al (2012) Functional genomics identifies neural stem cell sub-type expression profiles and genes regulating neuroblast homeostasis. Dev Biol 361:137-146. doi:10. 1016/j.ydbio.2011.10.020

Curtis CD, Brisson JA, DeCamillis MA et al (2001) Molecular characterization of Cephalothorax, the Tribolium ortholog of sex combs reduced. Genesis 30:12-20

Denes AS, Jekely G, Steinmetz PR et al (2007) Molecular architecture of annelid nerve cord supports common origin of nervous system centralization in bilateria. Cell 129:277-288

Dönitz J, Schmitt-Engel C, Grossmann D et al (2015) iBeetle-Base: a database for RNAi phenotypes in the red flour beetle Tribolium castaneum. Nucleic Acids Res 43:D720-D725. doi:10.1093/nar/ gku1054

Dreyer D, Vitt H, Dippel S et al (2010) 3D standard brain of the red flour beetle Tribolium castaneum: a tool to study metamorphic development and adult plasticity. Front Syst Neurosci 4:3. doi:10.3389/ neuro.06.003.2010

Egger B, Chell JM, Brand AH (2008) Insights into neural stem cell biology from flies. Philos Trans R Soc Lond B Biol Sci 363:3956. doi:10.1098/rstb.2006.2011

El Jundi B, Heinze S, Lenschow C et al (2009a) The locust standard brain: a 3D standard of the central complex as a platform for neural network analysis. Front Syst Neurosci 3:21. doi:10.3389/neuro.06. 021.2009

El Jundi B, Huetteroth W, Kurylas AE, Schachtner J (2009b) Anisometric brain dimorphism revisited: implementation of a volumetric 3D standard brain in Manduca sexta. J Comp Neurol 517:210-225. doi: $10.1002 /$ cne. 22150

Eriksson BJ, Stollewerk A (2010) Expression patterns of neural genes in Euperipatoides kanangrensis suggest divergent evolution of onychophoran and euarthropod neurogenesis. Proc Natl Acad Sci U S A 107:22576-22581. doi:10.1073/pnas.1008822108 
Farris SM, Strausfeld NJ (2003) A unique mushroom body substructure common to basal cockroaches and to termites. J Comp Neurol 456: 305-320. doi:10.1002/cne.10517

Gilles AF, Schinko JB, Averof M (2015) Efficient CRISPR-mediated gene targeting and transgene replacement in the beetle Tribolium castaneum. Dev Camb Engl 142:2832-2839. doi:10.1242/dev. 125054

Gould SJ (1977) Ontogeny and phylogeny. Harvard University Press, Harvard

Hanesch U, Fischbach K-F, Heisenberg M (1989) Neuronal architecture of the central complex in drosophila melanogaster. Cell Tissue Res 257:343-366. doi:10.1007/BF00261838

Hanström B (1925) Comparison between the brains of the newly hatched larva and the imago of Pieris brassicae. EntTidskr 46:43-52

Hanström B (1928) Vergleichende Anatomie des Nervensystems der Wirbellosen Tiere unter Berücksichtigung seiner Funktion. Springer, Berlin

Hartenstein V, Stollewerk A (2015) The evolution of early neurogenesis. Dev Cell 32:390-407. doi:10.1016/j.devcel.2015.02.004

Hartenstein V, Spindler S, Pereanu W, Fung S (2008) The development of the Drosophila larval brain. Adv Exp Med Biol 628:1-31. doi:10. 1007/978-0-387-78261-4_1

Heinze S (2015) Neuroethology: unweaving the senses of direction. Curr Biol CB 25:R1034-R1037. doi:10.1016/j.cub.2015.09.003

Hinke W (1961) Das relative postembryonale Wachstum der Hirnteile von Culex pipiens, Drosophila melanogaster und Drosophilamutanten. Z Für Morphol Ökol Tiere 50:81-118

Holmgren NF (1916) Zur vergleichenden Anatomie des Gehirns von Polychaeten, Onychophoren, Xiphosuren, Arachniden, Crustaceen, Myriapoden, und Insekten. Vorstudien zu einer Phylogenie der Arthropoden. K Sven Vetenskapsakad Handl 56:1-303

Homberg U (1985) Interneurons of the central complex in the bee brain Apis mellifera. J Insect Physiol 31:251-264

Homberg U (2008) Evolution of the central complex in the arthropod brain with respect to the visual system. Arthropod Struct Dev 37: 347-362. doi:10.1016/j.asd.2008.01.008

Homberg U, Hildebrand JG (1994) Postembryonic development of gamma-aminobutyric acid-like immunoreactivity in the brain of the sphinx moth manduca sexta. J Comp Neurol 339:132-149. doi:10.1002/cne.903390112

Ito $\mathrm{K}$, Shinomiya $\mathrm{K}$, Ito $\mathrm{M}$ et al (2014) A systematic nomenclature for the insect brain. Neuron 81:755-765. doi:10.1016/j.neuron. 2013.12.017

Jawlowski H (1936) Über den Gehirnbau der Käfer. Z Morph Ökol Tiere 32:67-91

Jenett A, Rubin GM, Ngo T-TB et al (2012) A GAL4-driver line resource for Drosophila neurobiology. Cell Rep 2:991-1001. doi:10.1016/j. celrep.2012.09.011

Jiang Y, Reichert H (2012) Programmed cell death in type II neuroblast lineages is required for central complex development in the Drosophila brain. Neural Dev 7:3. doi:10.1186/1749-8104-7-3

Kaiser A (2014) Immuncytochemische Färbungen und 3DRekonstruktionen am Zentralkomplex der Westlichen Honigbiene Apis mellifera

Kollmann M, Huetteroth W, Schachtner J (2011) Brain organization in Collembola (springtails). Arthropod Struct Dev 40:304-316. doi:10. 1016/j.asd.2011.02.003

Kumar A, Fung S, Lichtneckert R et al (2009) Arborization pattern of engrailed-positive neural lineages reveal neuromere boundaries in the Drosophila brain neuropil. J Comp Neurol 517:87-104. doi:10. 1002/cne. 22112

Kurylas AE, Rohlfing T, Krofczik S et al (2008) Standardized atlas of the brain of the desert locust, Schistocerca gregaria. Cell Tissue Res 333:125-145. doi:10.1007/s00441-008-0620-x
Loesel R, Nässel DR, Strausfeld NJ (2002) Common design in a unique midline neuropil in the brains of arthropods. Arthropod Struct Dev 31:77-91

Lorenzen MD, Berghammer AJ, Brown SJ et al (2003) piggyBac-mediated germline transformation in the beetle Tribolium castaneum. Insect Mol Biol 12:433-440

Lowe CJ, Wu M, Salic A et al (2003) Anteroposterior patterning in hemichordates and the origins of the chordate nervous system. Cell 113:853-865

Miller SC, Miyata K, Brown SJ, Tomoyasu Y (2012) Dissecting systemic RNA interference in the red flour beetle Tribolium castaneum: parameters affecting the efficiency of RNAi. PLoS One 7, e47431. doi: 10.1371/journal.pone.0047431

Mishra M, Oke A, Lebel C et al (2010) Pph13 and orthodenticle define a dual regulatory pathway for photoreceptor cell morphogenesis and function. Dev Camb Engl 137:2895-2904. doi:10.1242/dev.051722

Miyawaki K, Mito T, Sarashina I et al (2004) Involvement of wingless/ armadillo signaling in the posterior sequential segmentation in the cricket, Gryllus bimaculatus (Orthoptera), as revealed by RNAi analysis. Mech Dev 121:119-130

Nakamura T, Yoshizaki M, Ogawa S et al (2010) Imaging of transgenic cricket embryos reveals cell movements consistent with a syncytial patterning mechanism. Curr Biol CB 20:1641-1647. doi:10.1016/j. cub.2010.07.044

Panov AA (1959) Structure of the insect brain at successive stages of postembryonic development. II. The central body. Entomol Rev 38:276-283

Parker RJ, Auld VJ (2006) Roles of glia in the Drosophila nervous system. Semin Cell Dev Biol 17:66-77. doi:10.1016/j. semcdb.2005.11.012

Peel AD, Schanda J, Grossmann D et al (2013) Tc-knirps plays different roles in the specification of antennal and mandibular parasegment boundaries and is regulated by a pair-rule gene in the beetle Tribolium castaneum. BMC Dev Biol 13:25. doi:10.1186/1471213X-13-25

Pereanu W, Younossi-Hartenstein A, Lovick J et al (2011) Lineage-based analysis of the development of the central complex of the Drosophila brain. J Comp Neurol 519:661-689

Pfeiffer K, Homberg U (2014) Organization and functional roles of the central complex in the insect brain. Annu Rev Entomol 59:165-184. doi:10.1146/annurev-ento-011613-162031

Pfeiffer BD, Jenett A, Hammonds AS et al (2008) Tools for neuroanatomy and neurogenetics in Drosophila. Proc Natl Acad Sci U S A 105: 9715-9720. doi:10.1073/pnas.0803697105

Posnien N, Koniszewski NDB, Hein HJ, Bucher G (2011) Candidate gene screen in the red flour beetle Tribolium reveals Six 3 as ancient regulator of anterior median head and central complex development. PLoS Genet 7, e1002418. doi:10.1371/journal.pgen.1002416

Power ME (1943) The brain of Drosophila melanogaster. J Morphol 72: $517-559$

Rein K, Zöckler M, Mader MT et al (2002) The Drosophila standard brain. Curr Biol CB 12:227-231

Renn SC, Armstrong JD, Yang M et al (1999) Genetic analysis of the Drosophila ellipsoid body neuropil: organization and development of the central complex. J Neurobiol 41:189-207

Riebli N, Viktorin G, Reichert H (2013) Early-born neurons in type II neuroblast lineages establish a larval primordium and integrate into adult circuitry during central complex development in Drosophila. Neural Dev 8:6. doi:10.1186/1749-8104-8-6

Rybak J, Kuß A, Lamecker $\mathrm{H}$ et al (2010) The digital bee brain: integrating and managing neurons in a common 3D reference system. Front Syst Neurosci. doi:10.3389/fnsys.2010.00030

Sarrazin AF, Peel AD, Averof M (2012) A segmentation clock with twosegment periodicity in insects.

Schachtner J, Schmidt M, Homberg U (2005) Organization and evolutionary trends of primary olfactory brain centers in Tetraconata 
(Crustacea + Hexapoda). Arthropod Struct Dev 34:257-299. doi:10. 1016/j.asd.2005.04.003

Schinko JB, Weber M, Viktorinova I et al (2010) Functionality of the GAL4/UAS system in Tribolium requires the use of endogenous core promoters. BMC Dev Biol 10:53

Schinko J, Hillebrand K, Bucher G (2012) Heat shock-mediated misexpression of genes in the beetle Tribolium castaneum. Dev Genes Evol Dev Genes Evol: 287-98

Schmitt-Engel C, Schultheis D, Schwirz J et al (2015) The iBeetle largescale RNAi screen reveals gene functions for insect development and physiology. Nat Commun. doi:10.1038/ncomms 8822

Sheng G, Thouvenot E, Schmucker D et al (1997) Direct regulation of rhodopsin 1 by Pax-6/eyeless in Drosophila: evidence for a conserved function in photoreceptors. Genes Dev 11:1122-1131

Skeath JB, Thor S (2003) Genetic control of Drosophila nerve cord development. Curr Opin Neurobiol 13:8-15. doi:10.1016/S09594388(03)00007-2

Skoulakis EM, Kalderon D, Davis RL (1993) Preferential expression in mushroom bodies of the catalytic subunit of protein kinase A and its role in learning and memory. Neuron 11:197-208

Snodgrass RE (1935) Principles of insect morphology. McGRaw Hill, New York

Spindler SR, Hartenstein V (2010) The Drosophila neural lineages: a model system to study brain development and circuitry. Dev Genes Evol 220:1-10. doi:10.1007/s00427-010-0323-7

Steinmetz PR, Urbach R, Posnien N et al (2010) Six3 demarcates the anterior-most developing brain region in bilaterian animals. Evodevo 1:14

Stollewerk A (2016) A flexible genetic toolkit for arthropod neurogenesis. Philos Trans R Soc Lond B Biol Sci. doi:10.1098/rstb.2015.0044

Stollewerk A, Simpson P (2005) Evolution of early development of the nervous system: a comparison between arthropods. Bioessays 27: 874-883. doi:10.1002/bies.20276

Strausfeld NJ (1976) Atlas of an insect brain. Springer, Berlin Heidelberg

Strausfeld NJ (2005) The evolution of crustacean and insect optic lobes and the origins of chiasmata. Arthropod Struct Dev 34:235-256. doi:10.1016/j.asd.2005.04.001

Strausfeld NJ, Hirth F (2013) Deep homology of arthropod central complex and vertebrate basal ganglia. Science 340:157-161. doi:10. 1126/science. 1231828

Strausfeld NJ, Strausfeld CM, Loesel R et al (2006) Arthropod phylogeny: onychophoran brain organization suggests an archaic relationship with a chelicerate stem lineage. Proc Biol Sci 273:1857-1866. doi:10.1098/rspb.2006.3536

Strausfeld NJ, Sinakevitch I, Brown SM, Farris SM (2009) Ground plan of the insect mushroom body: functional and evolutionary implications. J Comp Neurol 513:265-291. doi:10.1002/cne.21948

Strauss R (2002) The central complex and the genetic dissection of locomotor behaviour. Curr Opin Neurobiol 12:633-638

Takemura S, Bharioke A, Lu Z et al (2013) A visual motion detection circuit suggested by Drosophila connectomics. Nature 500:175181. doi:10.1038/nature 12450

Technau GM, Berger C, Urbach R (2006) Generation of cell diversity and segmental pattern in the embryonic central nervous system of Drosophila. Dev Dyn 235:861-869

Tomer R, Denes AS, Tessmar-Raible K, Arendt D (2010) Profiling by image registration reveals common origin of annelid mushroom bodies and vertebrate pallium. Cell 142:800-809

Tomoyasu Y, Denell RE (2004) Larval RNAi in Tribolium (Coleoptera) for analyzing adult development. Dev Genes Evol 214:575-578

Trauner J, Schinko J, Lorenzen MD et al (2009) Large-scale insertional mutagenesis of a coleopteran stored grain pest, the red flour beetle
Tribolium castaneum, identifies embryonic lethal mutations and enhancer traps. BMC Biol 7:73

Ungerer P, Scholtz G (2008) Filling the gap between identified neuroblasts and neurons in crustaceans adds new support for Tetraconata. Proc Biol Sci 275:369-376. doi:10.1098/ rspb.2007.1391

Urbach R, Technau GM (2003) Molecular markers for identified neuroblasts in the developing brain of Drosophila. Development 130:3621-3637

Urbach R, Technau GM (2004) Neuroblast formation and patterning during early brain development in Drosophila. Bioessays 26:739-751

Viktorin G, Riebli N, Popkova A et al (2011) Multipotent neural stem cells generate glial cells of the central complex through transit amplifying intermediate progenitors in Drosophila brain development. Dev Biol 356:553-565. doi:10.1016/j.ydbio.2011.06.013

Watanabe T, Noji S, Mito T (2014) Gene knockout by targeted mutagenesis in a hemimetabolous insect, the two-spotted cricket Gryllus bimaculatus, using TALENs. Methods San Diego Calif 69:17-21. doi:10.1016/j.ymeth.2014.05.006

Weber H (1966) Grundriss der Insektenkunde, 4th edn. Gustav Fischer Verlag, Stuttgart

Wegerhoff R, Breidbach O (1992) Structure and development of the larval central complex in a holometabolous insect, the beetle Tenebrio molitor. Cell Tissue Res 268:341-358

Wegerhoff R, Breidbach O, Lobemeier M (1996) Development of locustatachykinin immunopositive neurons in the central complex of the beetle Tenebrio molitor. J Comp Neurol 375:157-166. doi:10. 1002/(SICI)1096-9861(19961104)375:1<157::AID-CNE10>3.0. $\mathrm{CO} ; 2-\mathrm{S}$

Wheeler SR, Carrico ML, Wilson BA et al (2003) The expression and function of the achaete-scute genes in Tribolium castaneum reveals conservation and variation in neural pattern formation and cell fate specification. Development 130:4373-4381

Wheeler SR, Carrico ML, Wilson BA, Skeath JB (2005) The Tribolium columnar genes reveal conservation and plasticity in neural precursor patterning along the embryonic dorsal-ventral axis. Dev Biol 279:491-500

Williams JLD (1975) Anatomical studies of the insect central nervous system: a ground plan of the midbrain and an introduction to the central complex in the locust Schistocerca gregaria (Orthoptera). J Zool 204:1269-1280

Williams JL, Güntner M, Boyan G (2005) Building the central complex of the grasshopper Schistocerca gregaria: temporal topology organizes the neuroarchitecture of the w, x, y, z tracts. Arthropod Struct Dev 34:97-110

Xiong WC, Okano H, Patel NH et al (1994) repo encodes a glial-specific homeo domain protein required in the Drosophila nervous system. Genes Dev 8:981-994

Yang JS, Awasaki T, Yu H-H et al (2013) Diverse neuronal lineages make stereotyped contributions to the Drosophila locomotor control center, the central complex: lineage analysis of central complex neurons. J Comp Neurol 521:2645-2662. doi:10.1002/cne.23339

Young JM, Armstrong JD (2010a) Building the central complex in Drosophila: the generation and development of distinct neural subsets. J Comp Neurol 518:1525-1541

Young JM, Armstrong JD (2010b) Structure of the adult central complex in Drosophila: organization of distinct neuronal subsets. J Comp Neurol 518:1500-1524. doi:10.1002/cne.22284

Zeng V, Ewen-Campen B, Horch HW et al (2013) Developmental gene discovery in a hemimetabolous insect: de novo assembly and annotation of a transcriptome for the cricket Gryllus bimaculatus. PLoS One 8, e61479. doi:10.1371/journal.pone.0061479 